\title{
Dietary factors and breast cancer risk: a case-control study among a population in Southern France
}

\author{
F. Bessaoud ${ }^{1}$, J. P. Daurès ${ }^{1}$ and M. Gerber ${ }^{2}$ \\ ${ }^{1}$ Laboratoire de Biostatistiques et d'Epidémiologie, Institut Universitaire de Recherche Clinique, Montpellier, France \\ and ${ }^{2}$ Centre de Recherche en Cancérologie, Centre Régional de Lutte Contre le Cancer, Montpellier, France
}

Findings on the relationship between foodstuffs and breast cancer remain inconsistent. Thus, the association between diet and breast cancer has been examined using a different statistical dose-response approach.

Between 2002 and 2004 a total of 437 cases and 922 controls matched according to age and area of residence were interviewed. Diet was measured by a validated FFQ organised mainly by food groups. OR and $95 \%$ CI were computed across various dietary intake levels identified by a free-knot spline for logistic model and adjusted for established risk factors of breast cancer and total energy intake. Freeknot splines allow investigation of the dose-response relationship by detecting the non-linear effects of the explanatory variable and determining threshold values. Thus, continuous estimates were calculated when the relationship was linear and the threshold was retained as a cut off when the spline analysis indicated one to three knots.

Total consumption of cooked vegetables, legumes and fish were associated with a non-significant decrease in breast cancer risk. There was an approximate twofold increase in the risk of breast cancer with each additional $100 \mathrm{~g}$ meat consumption/d. Cereal intake $>44 \mathrm{~g} / \mathrm{d}$ (e.g. two slices of bread) significantly decreased breast cancer risk. The consumption of oil olive was associated with a significant decrease in breast cancer for a moderate consumption. Intake of dairy products, raw vegetables and fruit did not show an association with breast cancer risk.

\begin{tabular}{|c|c|c|c|c|c|c|}
\hline Foods & Dose-response relationship & Thresholds & Type & Modalities (g/d) & OR & $95 \% \mathrm{CI}$ \\
\hline Fruit & Linear & - & Continuous & 100 & 1.02 & $0.95,1.10$ \\
\hline Meat & Linear & - & Continuous & 100 & 1.95 & $1.08,3.53$ \\
\hline \multirow{2}{*}{$\begin{array}{l}\text { Cooked } \\
\text { vegetables }\end{array}$} & \multirow[t]{2}{*}{ Linear with one knot } & \multirow[t]{2}{*}{105} & \multirow[t]{2}{*}{ Discrete } & $\leq 105$ & 1 & \\
\hline & & & & $>105$ & 0.86 & $0.60,1.24$ \\
\hline \multirow[t]{2}{*}{ Cereals } & \multirow[t]{2}{*}{ Linear with one knot } & \multirow[t]{2}{*}{44} & \multirow[t]{2}{*}{ Discrete } & $\leq 44$ & 1 & \\
\hline & & & & $>44$ & 0.29 & $0.15,0.55$ \\
\hline \multirow[t]{2}{*}{ Fish } & \multirow[t]{2}{*}{ Linear with one knot } & \multirow[t]{2}{*}{23} & \multirow[t]{2}{*}{ Discrete } & $\leq 23$ & 1 & \\
\hline & & & & $>23$ & 0.80 & $0.61,1.06$ \\
\hline \multirow[t]{4}{*}{ Olive oil } & \multirow[t]{4}{*}{ Linear with three knots } & 2 & \multirow[t]{4}{*}{ Discrete } & $\leq 2$ & 1 & \\
\hline & & 11.6 & & $>11.6$ & 0.53 & $0.35,0.84$ \\
\hline & & \multirow[t]{2}{*}{20.5} & & $11.6-20.5$ & 0.60 & $0.37,0.96$ \\
\hline & & & & $>20.5$ & 0.71 & $0.44,1.14$ \\
\hline
\end{tabular}

In conclusion, the results showed an association between red meat consumption and breast cancer risk, and cereals and olive oil were associated with a reduction in breast cancer risk. In future, a new approach of analysing dietary patterns rather than dietary food should be developed. 